\title{
Voltammetric/amperometric detection of salicylic acid in water on carbon nanotubes-epoxy composite electrodes
}

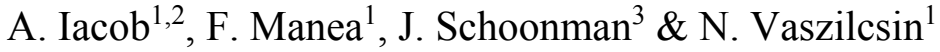 \\ ${ }^{1}$ Politehnica University of Timisoara, Romania \\ ${ }^{2}$ S.C. DATCOMP S.R.L, Romania \\ ${ }^{3}$ Materials for Energy Conversion and Storage, Department of Chemical \\ Engineering, Delft University of Technology, The Netherlands
}

\begin{abstract}
This study aimed to develop the detection protocol for the quantitative determination of salicylic acid (SA) in water. A carbon nanotubes-epoxy composite (CNTE) electrode was tested for the development of the SA detection protocol. The electrochemical behaviour of SA on a CNTE electrode has been studied using the cyclic voltammetry $(\mathrm{CV})$ technique. Also, the study of $\mathrm{pH}$ effect by $\mathrm{CV}$ showed that no significant effect was found. Differential-pulsed voltammetry (DPV) and square-wave voltammetry (SWV) techniques were employed for the optimization of the detection protocol. The optimized SWV technique application assumes the step potential of $0.005 \mathrm{~V}$, the modulation amplitude of $0.05 \mathrm{~V}$ and the frequency of $50 \mathrm{~Hz}$. In order to use this detection protocol for the in-field detection application, the possibility of using this composite electrode in real surface water without adding the supporting electrolyte has been tested. The same electroanalytical parameters for SA detection in real surface water and tap water were achieved without any interference, which denotes the microelectrode array behaviour of the composite electrode. This behaviour confers a great potential of this composite electrode for in-field direct detection of salicylic acid and also, for the indirect detection of acetylsalicylic acid from surface water.
\end{abstract}

Keywords: salicylic acid, carbon nanotubes-epoxy composite electrodes, voltammetric detection, in-field detection, water monitoring. 


\section{Introduction}

Salicylic acid (SA) known as 2-hydrobenzoic acid is an organic micro molecular compound, which is widely distributed in various plants, as an endogenous signaling molecule, playing an important role in the regulation of many physiological processes in plants such as flowering, heat production, seed germination, membrane permeability and ion adsorption. At the same time, SA is an important chemical and curative raw material which has been widely used in cosmetics [1], lotions and the pharmaceuticals industry [2] due to its distinct exfoliating and antiseptic, antipyretic, analgesic, and anti-inflammatory properties. SA is also a primary hydrolysate of acetylsalicylic acid (ASA) which is commonly used as anti-inflammatory medicine, and SA determination can be regarded as an indirect determination of ASA. Salycilic acid (SA) is considered as a pharmaceutical intermediate to produce various medicines and also, as a metabolite intermediate of these medicines. Its presence at high concentration levels in water can cause serious environmental and health problems [3, 4]. Therefore, the effective and convenient determination of SA represents a very important issue of research.

Many analytical methods for SA determination have been described in literature, such as fluorescence spectrometry $[5,6]$, high performance liquid chromatography [7], potentiometry [8], amperometry [9], voltammetry [10], and enzymatic methods [11, 12]. However, most of the above mentioned methods need a series of sample pretreatments and high cost complicated operations or show poor efficiency.

Recently, the determination of SA with voltammetric/amperometric methods has caught much attention because of their sensitivity and simplicity. Taking into consideration that carbon nanotube (CNT)-based electrodes have exhibited good performances for the voltammetric/amperometric detections reported in our previous study $[13,14]$, in this study, the voltammetric determination of SA at carbon nanotubes-epoxy (CNTE) composite electrode has been investigated using cyclic voltammetry (CV), differential-pulsed voltammetry and squarewave voltammetry (SWV).

\section{Experimental}

A carbon nanotubes-epoxy composite (CNTE) electrode tested to develop the detection protocol of SA from aqueous solution and real waters was obtained by two roll mills procedure. The details regarding the preparation, morphological and electrical characterization have been presented by our group elsewhere [14]. It should be mentioned that the CNT loading within the epoxy matrix was $20 \%$, wt.

All electrochemical characterization and detection experiments were carried out in a $50 \mathrm{ml}$ three-electrode cell by Methrom type, which consisted of a saturated calomel reference electrode, platinum contraelectrode and CNTE working electrode. The supporting electrolyte used for the electrochemical experiments was $0.1 \mathrm{M} \mathrm{Na}_{2} \mathrm{SO}_{4}$ and respectively, $0.1 \mathrm{M} \mathrm{NaOH}$. Sodium 
sulphate, sodium hydroxide and salicylic acid were analytical grade provided by Merck, Germany. Cyclic voltammetry (CV), differential-pulsed voltammetry (DPV) and square-wave voltammetry (SWV) are the electrochemical techniques used for the electrochemical characterization of the electrode and for the detection experiments.

\section{Results and discussions}

\subsection{Electrochemical behaviour of SA on a CNTE electrode by cyclic voltammetry}

In order to develop the voltammetric protocol for salicylic acid (SA) detection, it is important to select the most suitable supporting electrolyte, especially for the electrochemical characterization of the electrode material in the presence of the targeted analyte related to the detection approach. Taking into account our previously reported papers $[14,15], 0.1 \mathrm{M} \mathrm{Na}_{2} \mathrm{SO}_{4}$ and $0.1 \mathrm{M} \mathrm{NaOH}$ supporting electrolytes were tested for studying the electrochemical behavior of a CNTE electrode in the presence of salicylic acid (SA). Figure 1 shows the cyclic voltammograms recorded in $0.1 \mathrm{M} \mathrm{Na}_{2} \mathrm{SO}_{4}$ supporting electrolyte (curve 1) in the presence of $0.6 \mathrm{mM}$ salicylic acid (SA) (curve 2) and $0.1 \mathrm{M} \mathrm{NaOH}$ supporting electrolyte (curve 3) and also, in the presence of $0.6 \mathrm{mM}$ salicylic acid (SA) (curve 4). CV shapes show that a CNTE composite electrode exhibits several differences of electrochemical behavior in different supporting electrolytes. Thus, as we expected, in $0.1 \mathrm{M} \mathrm{NaOH}$ supporting electrolyte the background current corresponding to the capacitive component is higher in comparison with $0.1 \mathrm{M} \mathrm{Na}_{2} \mathrm{SO}_{4}$ supporting electrolyte, and the oxygen evolution occurred at the

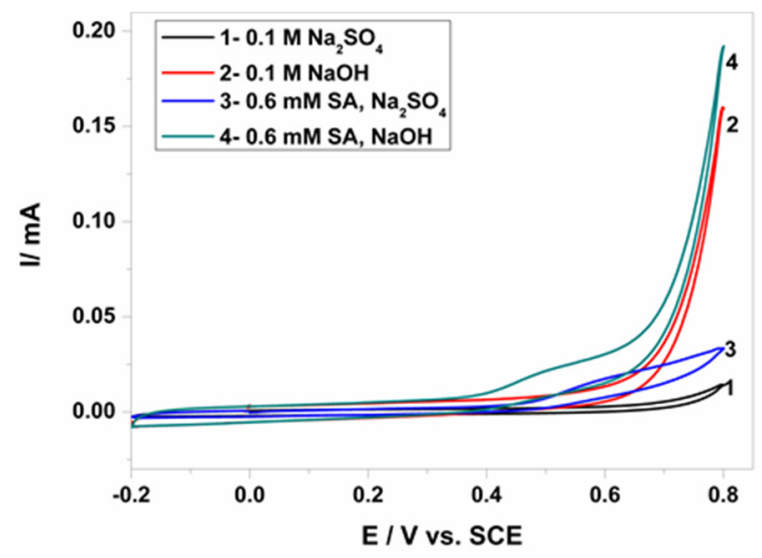

Figure 1: CVs of the CNTE composite electrode in $0.1 \mathrm{M} \mathrm{Na}_{2} \mathrm{SO}_{4}$ supporting electrolyte (1) and in the presence of $0.6 \mathrm{mM} \mathrm{SA}$ (3), and in $0.1 \mathrm{M}$ $\mathrm{NaOH}$ supporting electrolyte (2) and in the presence of $0.6 \mathrm{mM}$ SA (4). 
lower overpotential value $(0.68 \mathrm{~V}$ in comparison with $0.72 \mathrm{~V}$ vs. SCE determined in $0.1 \mathrm{Na}_{2} \mathrm{SO}_{4}$ supporting electrolyte). These aspects are not desired for the electroanalysis, but a lower overpotential for SA oxidation is sufficient in $0.1 \mathrm{M} \mathrm{NaOH}\left(0.5 \mathrm{~V}\right.$ vs. $0.6 \mathrm{~V} / \mathrm{SCE}$ in $\left.0.1 \mathrm{M} \mathrm{Na}_{2} \mathrm{SO}_{4}\right)$, which gave it the potential for application in the electroanalysis, regarding interference avoiding and the simultaneous detection in the presence of other analytes. However, taking into consideration $\mathrm{pH}$ and the composition of the real water, the further experiments were performed in $0.1 \mathrm{M} \mathrm{Na}_{2} \mathrm{SO}_{4}$ supporting electrolyte.

Figure 2(a) depicts a series of CVs obtained for SA standard solution recorded over the concentration range of $0.02 \mathrm{mM}-1.2 \mathrm{mM}$. These results show that the oxidation process of SA occurred at the potential value of $+0.6 \mathrm{~V}$ vs. SCE and the lack of the corresponding cathodic peak informed the irreversibility of this oxidation process. The anodic peak increased progressively with SA concentration and the calibration plot data of anodic current peaks versus concentration of SA exhibited good linearity and sensitivity (see Table 1 and Figures 2(c) and (d)) over two SA concentration ranges because no linear

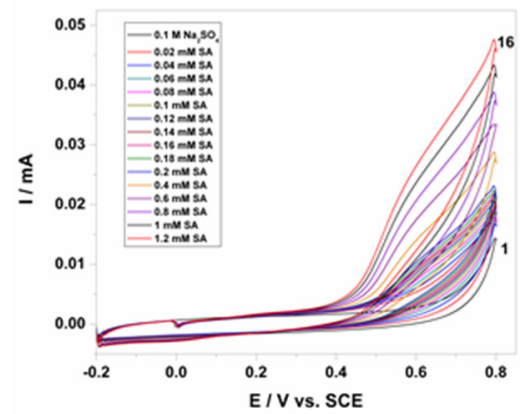

(a)

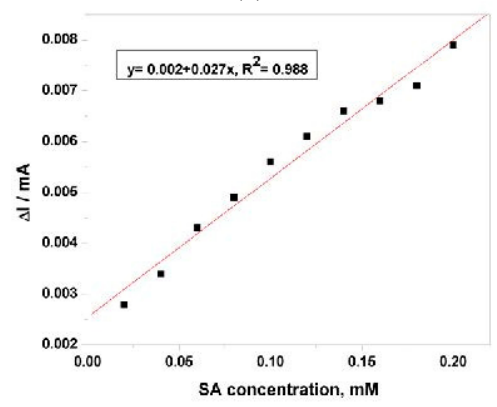

(c)

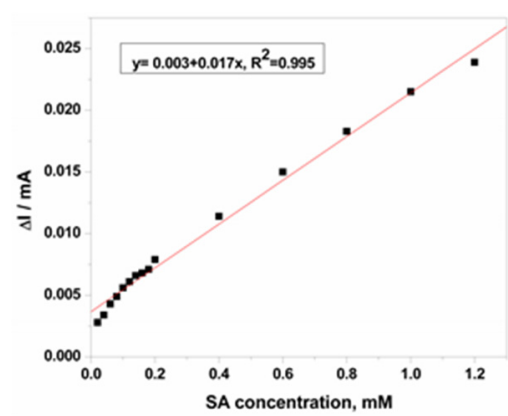

(b)

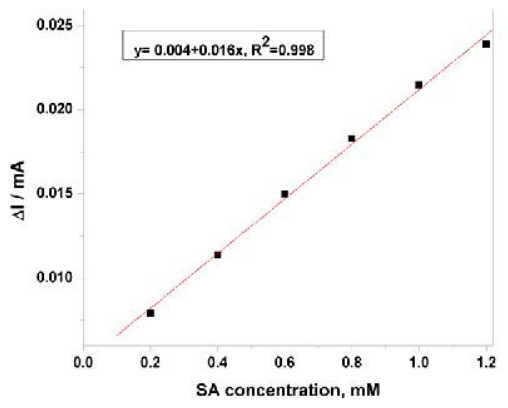

(d)

Figure 2: (a) CVs of the CNTE composite electrode in $0.1 \mathrm{M} \mathrm{Na}_{2} \mathrm{SO}_{4}$ supporting electrolyte (curve 1) and in the presence of: $0.02,0.04$, $0.06,0.08,0.1,0.12,0.14,0.16,0.18,0.2,0.4,0.6,0.8,1,1.2 \mathrm{mM}$ $\mathrm{SA}$; scan rate $0.05 \mathrm{Vs}^{-1}$. (b) Calibration plots of anodic peak current recorded at $\mathrm{E}=+0.6 \mathrm{~V} / \mathrm{SCE}$ vs. SA concentrations. 
dependence of the anodic current versus SA concentration for the whole studied concentration range was achieved (see Figure 2(b)). The linear dependence between anodic oxidation current peak and SA concentration informed about diffusion-controlled oxidation process, which is required for the application in the voltammetric detection.

After this preliminary discussion of cyclic voltammetry data, and confirmation of a diffusely-controlled anodic process, more detailed investigations with the electroanalytical application purposes were conducted using two other different techniques, differential-pulsed voltammetry (DPVs) and square-wave voltammetry (SWV). These techniques are characterized by a great potential to improve the electroanalytical parameters' characteristics to SA voltammetric detection.

A series of the anodic DPVs presented in Figure 3(a) involving SA concentration effect at CNTE composite electrode in $0.1 \mathrm{M} \mathrm{Na}_{2} \mathrm{SO}_{4}$ supporting electrolyte were recorded over the concentration range of $0.02 \mathrm{mM}-1.2 \mathrm{mM}$

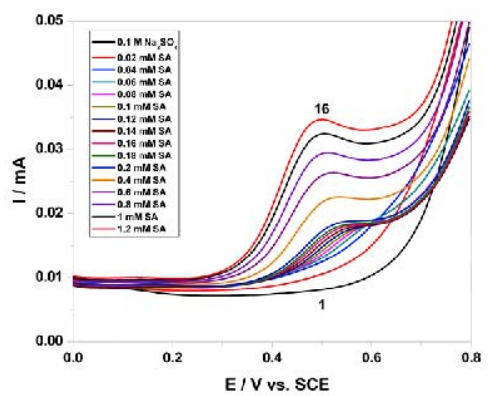

(a)

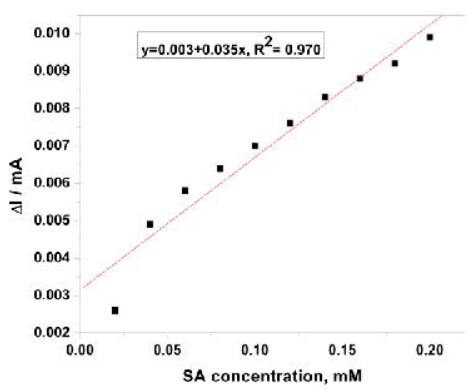

(c)

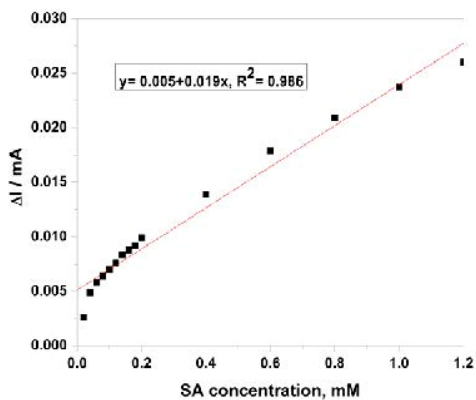

(b)

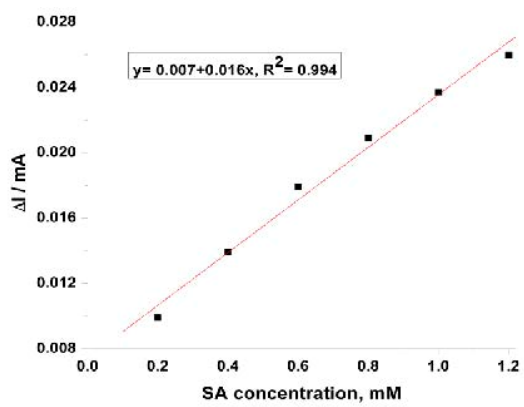

(d)

Figure 3: (a) DPVs of the CNTE composite electrode in $0.1 \mathrm{M} \mathrm{Na} \mathrm{Na}_{4}$ supporting electrolyte (curve 1) (modulation amplitude $0.1 \mathrm{~V}$, step potential $0.01 \mathrm{~V}$ ), and a potential scan rate $0.05 \mathrm{Vs}^{-1}$ and in the presence of: $0.02,0.04,0.06,0.08,0.1,0.12,0.14,0.16,0.18,0.2$, $0.4,0.6,0.8,1,1.2 \mathrm{mM}$ SA concentrations. (b) Calibration plots of the anodic current recorded at ca. $\mathrm{E}=+0.52 \mathrm{~V}$ vs. SA concentration in the concentration range: (b) $0.02-1.2 \mathrm{mM} \mathrm{SA}$, (c) $0.02-0.2 \mathrm{mM}$ SA (d) 0.2-1.2 mM SA. 
SA similar to $\mathrm{CV}$ investigation using SA standard solution. The two SA concentrations ranges established based on the linear dependence of the anodic current versus SA concentration were the same as for CV results (see Figures 3(c) and (d)). In comparison with CV results, this technique exhibited the advantage of the lower overpotential for SA oxidation $(+0.52 \mathrm{~V}$ vs. $+0.6 \mathrm{~V} / \mathrm{SCE})$. The calibration plot showed a slight better sensitivity of $0.035 \mathrm{~mA} \cdot \mathrm{mM}^{-1}$ and a good linearity with a correlation coefficient of 0.970 . The LOD value of $0.009 \mathrm{mM}$ is very close to the one obtained when using the CV technique.

The adsorption capacity of a CNTE composite electrode towards SA has been investigated envisaging a possible enhancement of the SA detection in relation with the lowest limit of detection and the sensitivity. The adsorption study was carried out by maintaining the electrode surface within $0.4 \mathrm{mM} \mathrm{SA}$ in $0.1 \mathrm{Na}_{2} \mathrm{SO}_{4}$ supporting electrolyte at open circuit potential at a different accumulation time, and then DPV was recorded. The results are presented in Figure 4, and it can be seen that the optimum accumulation time is 30 minutes, at which the steady-state is reached. At longer accumulation time, the current corresponding to the SA oxidation decreased because of a possible oversaturation of the electrode surface with SA, which can lead also to fouling of the electrode. Under these working conditions, an enhancement factor of 1.9 was achieved and the further experiment involved a preconcentration step for 30 minutes before applying DPV.

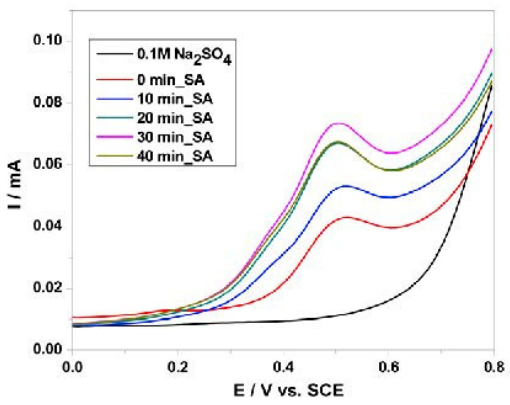

(a)

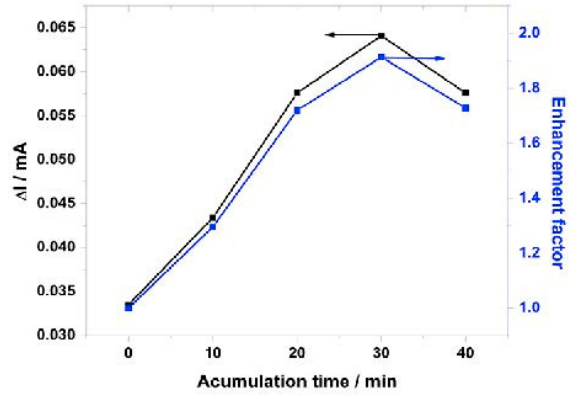

(b)

Figure 4: DPVs of the CNTE composite electrode (modulation amplitude $0.1 \mathrm{~V}$, step potential $0.01 \mathrm{~V}$ ), and a potential scan rate $0.05 \mathrm{Vs}^{-1}$ in $0.1 \mathrm{M} \mathrm{Na}_{2} \mathrm{SO}_{4}$ supporting electrolyte and $0.4 \mathrm{mM} \mathrm{SA}$ after different accumulation times: $0 \mathrm{~min} ; 10 \mathrm{~min} ; 20 \mathrm{~min} ; 30 \mathrm{~min} ; 40 \mathrm{~min}$. (b) Peak current responses and enhancement factor for the detection of $0.4 \mathrm{mM}$ PCP at CNTE composite electrode as a function of the accumulation time recorded at $\mathrm{E}=+0.46 \mathrm{~V} / \mathrm{SCE}$.

In Figure 5 is shown a series of DPVs on CNTE composite electrode recorded under the optimum conditions of the preconcentration scheme that assume the accumulation time of 30 minutes within SA concentrations ranging from 0.02 to 
$0.1 \mathrm{mM}$ SA and a better sensitivity and the lowest limit of detection were achieved (see Table 1).

The other pulsed technique tested to improve the electroanalytical performance for SA detection on CNTE composite electrode is square-wave voltammetry (SWV). Figure 6(a) depicts a series of SWV recorded on CNTE composite electrode over the same SA concentration range (0.02-1.2 mM SA) under optimized conditions, i.e., modulation amplitude $0.05 \mathrm{~V}$, step potential $0.005 \mathrm{~V}$, frequency of $50 \mathrm{~Hz}$. Figure 6(b) corresponds to the analytical curve,

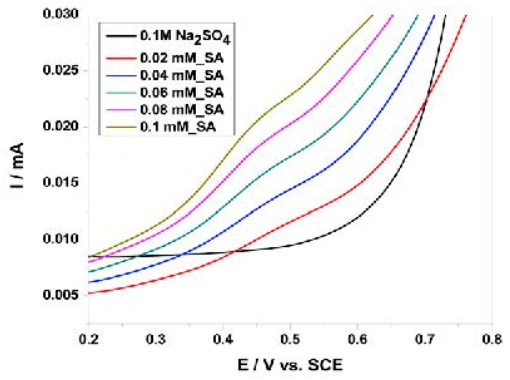

(a)

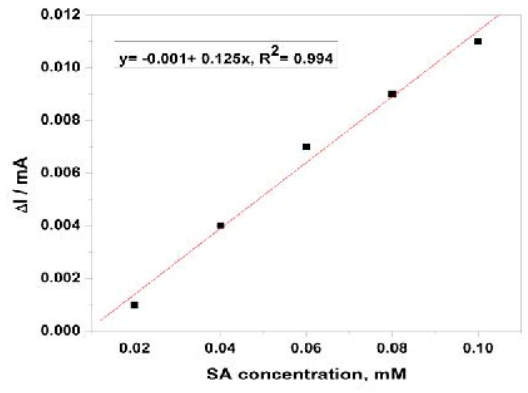

(b)

Figure 5: (a) DPVs of the CNTE composite electrode (modulation amplitude $0.1 \mathrm{~V}$, step potential $0.01 \mathrm{~V}$ ), and a potential scan rate $0.05 \mathrm{Vs}^{-1}$ in $0.1 \mathrm{M} \mathrm{Na}_{2} \mathrm{SO}_{4}$ supporting electrolyte and different SA concentrations: $0.02,0.04,0.06,0.08,0.1 \mathrm{mM} \mathrm{SA}$ after $30 \mathrm{~min}$ of accumulation time at $\mathrm{E}=+0.46 \mathrm{~V} / \mathrm{SCE}$. (b) Calibration plots of anodic peak current recorded at $\mathrm{E}=+0.46 \mathrm{~V} / \mathrm{SCE}$ vs. SA concentrations.

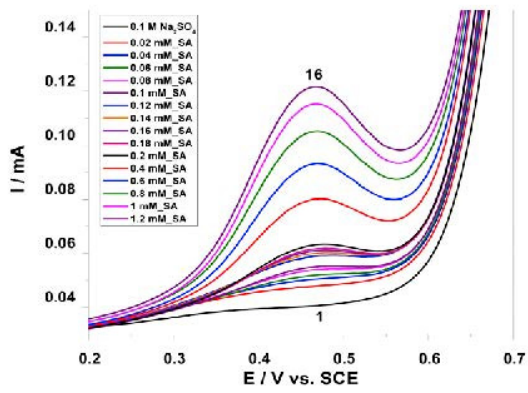

(a)

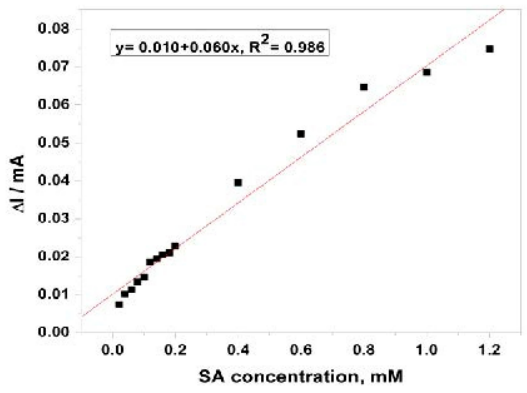

(b)

Figure 6: (a) SWVs of the CNTE composite electrode in $0.1 \mathrm{M} \mathrm{Na} \mathrm{Na}_{4}$ supporting electrolyte (curve 1) (modulation amplitude $0.05 \mathrm{~V}$, step potential $0.005 \mathrm{~V}$, frequency of $50 \mathrm{~Hz}$ ), and in the presence of: 0.02 , $-1.2 \mathrm{mM}$ SA concentrations. (b) Calibration plots of the anodic current recorded at $\mathrm{E}=+0.46 \mathrm{~V}$ vs. $\mathrm{SA}$ concentration. 
that is, the linear dependence of useful current with SA concentration ranged between 0.02 and $1.2 \mathrm{mM} \mathrm{SA}$. For the SA concentration higher than $1.2 \mathrm{mM}$ a non-linear dependence was noticed because of the saturation electrode surface with SA and/or fouling effect of the electrode surface.

The lowest limit of detection (LOD) and the lowest limit of quantification (LQ) have been calculated according to $3 \sigma /$ slope, and respectively, $10 \sigma /$ slope criteria, where $\sigma$ was estimated as the standard deviation applied to the voltammetric signal measured for the blank, the slope of the straight line in the analytical curve and RSD ranged between 1 and 3\%.

The electroanalytical parameters determined for the voltammetric detection of SA on CNTE composite electrode in $0.1 \mathrm{M} \mathrm{Na}_{2} \mathrm{SO}_{4}$ supporting electrolyte are gathered in Table 1.

Table 1: The electroanalytical performance of CNTE composite electrode for the voltammetric detection of $\mathrm{SA}$ in $0.1 \mathrm{M} \mathrm{Na}_{2} \mathrm{SO}_{4}$ supporting electrolyte.

\begin{tabular}{|c|c|c|c|c|c|c|c|}
\hline $\begin{array}{c}\text { Peak } \\
\text { potential }\end{array}$ & $\begin{array}{c}\text { Technique } \\
\text { used }\end{array}$ & $\begin{array}{l}\text { Concentration } \\
\text { range }(\mathrm{mM})\end{array}$ & $\begin{array}{l}\text { Sensitivity } \\
\left(\mathrm{mA} / \mathrm{mM}^{-1}\right)\end{array}$ & $\begin{array}{c}\text { Correlation } \\
\text { coefficient } \\
\left(\mathrm{R}^{2}\right)\end{array}$ & $\begin{array}{l}\text { LOD } \\
(\mathrm{mM})\end{array}$ & $\begin{array}{c}\mathrm{LQ} \\
(\mathrm{mM})\end{array}$ & $\begin{array}{l}\text { RSD } \\
{[* *]} \\
(\%)\end{array}$ \\
\hline$+0.60 \mathrm{~V}$ & $\mathrm{CV}$ & $0.02-1.2$ & 0.017 & 0.995 & 0.012 & 0.041 & 2.8 \\
\hline \multirow{3}{*}{$+0.52 \mathrm{~V}$} & \multirow{3}{*}{$\begin{array}{c}\mathrm{DPV} \\
\mathrm{Sp}=0.01 \mathrm{~V} \\
\mathrm{Ma}=0.1 \mathrm{~V}\end{array}$} & $0.02-1.2$ & - & - & - & - & - \\
\hline & & $0.02-0.2$ & 0.035 & 0.970 & 0.009 & 0.031 & 1.315 \\
\hline & & $0.2-1.2$ & 0.016 & 0.994 & 0.015 & 0.055 & 1.315 \\
\hline$+0.46 \mathrm{~V}$ & $\begin{array}{c}\text { Prec./ DPV } \\
\mathrm{Sp}=0.01 \mathrm{~V} \\
\mathrm{Ma}=0.1 \mathrm{~V}\end{array}$ & $0.02-0.1$ & 0.125 & 0.994 & 0.002 & 0.04 & 2.90 \\
\hline$+0.46 \mathrm{~V}$ & $\begin{array}{c}\mathrm{SWV} \\
\mathrm{Sp}=0.005 \mathrm{~V} \\
\mathrm{Ma}=0.05 \mathrm{~V} \\
\mathrm{~F}=50 \mathrm{~Hz}\end{array}$ & $0.02-1.2$ & 0.060 & 0.986 & 0.005 & 0.016 & 0.250 \\
\hline
\end{tabular}

Several literature data underline that the carbon based composite electrode can be regarded either ordered (array) or randomized micro/nanoelectrode ensembles [16, 17]. Under these circumstances, the diffusion flux toward microelectrodes ensembles depend strongly on the experimental timescale. Moreover, the specific micro/nano-dispersed nature of the investigated carbonbased composite electrode suggested a presumptive way to discuss the corresponding electrochemical data considering the typical aspects regarding the behavior of randomized or array structured micro/nano-electrodes systems. The most important characteristics are linked to the application of this electrode in the detection of the real water without deliberately adding the supporting electrolyte.

Two different issues have been taken into consideration for testing CNTE composite electrode for SA detection in the tap water and in the surface water (Bega River from Timisoara city, Romania). The first issue was the possibility of the direct analysis of pharmaceutical compounds in surface water envisaging insitu determination. The second issue referred to the certification of the 
micro/nanoelectrode array behavior of CNTE composite electrode by SA detection in tap water, without supporting electrolyte.

DPV and SWV techniques were applied for real surface water and tap water, which were spiked with known concentrations of salicylic acid. As an example, a series of DPVs recorded at CNTE in tap water without adding a supporting electrolyte is shown in Figure 7. Similar sensitivity with that reached in $0.1 \mathrm{M}$ $\mathrm{Na}_{2} \mathrm{SO}_{4}$ supporting electrolyte was achieved, which proved the microelectrode array behavior. Similar voltammograms were recorded in Bega River (the results are not shown here), and all electroanalytical parameters are gathered in Table 2. These results confirm the possibility of applying this protocol using a CNTE electrode for in-field detection application for the water monitoring.

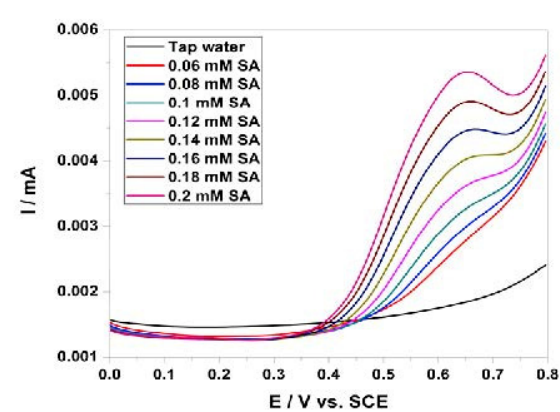

(a)

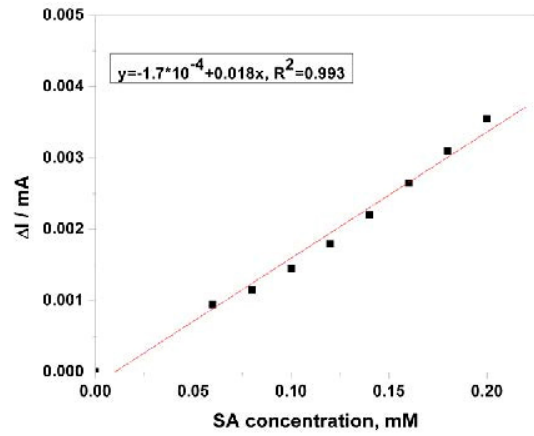

(b)

Figure 7: (a) DPVs of the CNTE composite electrode in tap water without supporting electrolyte (black curve) (modulation amplitude $0.1 \mathrm{~V}$, step potential $0.01 \mathrm{~V}$ ), and a potential scan rate $0.05 \mathrm{Vs}^{-1}$ and in the presence of: $0.06,0.08,0.1,0.12,0.14,0.16,0.18,0.2 \mathrm{mM} \mathrm{SA}$ concentrations. (b) Calibration plots of the anodic current recorded at $\mathrm{E}=+0.65 \mathrm{~V}$ vs. SA concentration.

Table 2: The electroanalytical parameters for SA direct detection at CNTE composite electrode in Bega River and the tap water, without supporting electrolyte.

\begin{tabular}{|c|c|c|c|c|c|c|c|}
\hline $\begin{array}{c}\text { Aqueous } \\
\text { media }\end{array}$ & $\begin{array}{c}\text { Peak } \\
\text { potential }\end{array}$ & $\begin{array}{c}\text { Technique } \\
\text { used }\end{array}$ & $\begin{array}{c}\text { Concentration } \\
\text { range }(\mathrm{mM})\end{array}$ & $\begin{array}{l}\text { Sensitivity } \\
\left(\mathrm{mA} / \mathrm{mM}^{-1}\right)\end{array}$ & $\begin{array}{c}\text { Correlation } \\
\text { coefficient } \\
\left(\mathrm{R}^{2}\right)\end{array}$ & $\begin{array}{l}\text { LOD } \\
\mathrm{mM}\end{array}$ & $\begin{array}{l}\text { RSD } \\
{[* *]} \\
(\%)\end{array}$ \\
\hline \multirow[b]{2}{*}{$\begin{array}{l}\text { Bega } \\
\text { River }\end{array}$} & $+0.52 \mathrm{~V}$ & $\begin{array}{c}\text { DPV } \\
\mathrm{Sp}=0.01 \mathrm{~V} \\
\mathrm{Ma}=0.1 \mathrm{~V}\end{array}$ & $0.2-1.2$ & 0.026 & 0.991 & 0.005 & 0.980 \\
\hline & $+0.56 \mathrm{~V}$ & $\begin{array}{c}\text { SWV } \\
\mathrm{Sp}=0.005 \mathrm{~V} \\
\mathrm{Ma}=0.05 \\
\mathrm{~V} \mathrm{~F}=50 \mathrm{~Hz}\end{array}$ & $0.2-1.2$ & 0.073 & 0.999 & 0.004 & 0.186 \\
\hline \multirow{2}{*}{$\begin{array}{c}\text { Tap } \\
\text { water }\end{array}$} & $+0.65 \mathrm{~V}$ & \multirow{2}{*}{$\begin{array}{c}\text { DPV } \\
\mathrm{Sp}=0.01 \mathrm{~V} \\
\mathrm{Ma}=0.1 \mathrm{~V}\end{array}$} & $0.06-0.2$ & 0.018 & 0.993 & 0.008 & 2.702 \\
\hline & $+0.52 \mathrm{~V}$ & & $0.2-1.2$ & 0.029 & 0.999 & 0.010 & 3.030 \\
\hline
\end{tabular}




\section{Conclusions}

Carbon nanotubes-epoxy composite electrode allowed for detecting salicylic acid (SA) in both a neutral and alkaline medium. The optimum operating conditions were determined as square-wave voltammetry technique employed under step potential of $0.005 \mathrm{~V}$, the modulation amplitude of $0.05 \mathrm{~V}$ and the frequency of $50 \mathrm{~Hz}$. A preconcentration step assured by maintaining for 30 minutes the electrode surface within SA at open circuit potential enhanced the electroanalytical parameters of sensitivity and the lowest limit of detection for SA detection. In addition, CNTE composite electrode manifested the microelectrode array behavior in relation with the direct detection of SA in real surface and tap waters, without supporting electrolyte. Moreover, the results of the SA detection direct in Bega River, also without the supporting electrolyte adding given to this electrode a real potential for in-situ detection application.

\section{Acknowledgements}

This work was partially supported by the strategic grant POSDRU/159/1.5 /S/137070 (2014) of the Ministry of National Education, Romania, co-financed by the European Social Fund - Investing in People, within the Sectoral Operational Programme Human Resources Development 2007-2013, and partially by the PN-II- ID-PCE-165/2011 and PNII-PCCA-60/2012.

\section{References}

[1] Yu, B.S., Nie, L.H., Yao, S.Z. Ion-chromatographic determination of salicylate in human serum with a bulk acoustic-wave sensor as detector. Journal of High Resolution Chromatography, 20, pp. 227-130, 1997.

[2] Ehrendorfer, M., Sontag, G., Pittner, F. Determination of salicylate in beverages and cosmetics by use of an amperometric biosensor. Fresenius' Journal of Analytical Chemistry, 356, pp. 75-79, 1996.

[3] Flaherty, S., Wark, S., Street, G., Farley, J. W., Brumley, W. C. Investigation of $\mathrm{CE} / \mathrm{LIF}$ as a Tool in the Characterization of Sewage Effluent for Fluorescent Acidics: Determination of Salicylic Acid. Electrophoresis, 23, pp. 2327-2332, 2002.

[4] Gangwang, G., Liu, G., Liu, H., Zhang, N., Wang, Y. Photodegradation of salicylic acid in aquatic environment: Effect of different form of nitrogen. Science of the Total Environment, 435-436, pp. 573-577, 2012.

[5] de la Peña, A.M., Salinas, F., Meras, I.D. Simultaneous determination of salicylic and salicyluric acids in urine by first-derivative synchronous fluorescence spectroscopy. Analytical Chemistry, 60, pp. 2493-2496, 1988

[6] Villari, A., Micali, M., Fresta, M., Puglisi, G. Spectrofluorimetry at zero angle: determination of salicylic acid in an acetylsalicylic acid pharmaceutical formulation. .Analyst, 119, pp.1561-1565, 1994. 
[7] Kees, F., Jehnich, D., Grobecker, H. Simultaneous determination of acetylsalicylic acid and salicylic acid in human plasma by high performance liquid chromatography, Journal of Chromatography B, 677, pp. 172-177, 1996.

[8] Kubota, L.T., Fernandes, J.C.B., Rover, L., Neto, G.D. Determination of acetylsalicylic acid by FIA-potentiometric system in drugs after on-line hydrolysis. Talanta, 50, pp. 661-667, 1999.

[9] Newmayr, M., Friedrich, O., Sontag, G., Pittner, F. Flow-injection analysis with electrochemical detection for determination of salicylic acid in pharmaceutical preparations. Analytica Chimica Acta, 273, pp. 469-475 1993.

[10] Fung, Y.S., Luk, S.F. Determination of salicylic acid in pharmaceutical formulations and foods by differential-pulse voltammetry using a glassy carbon electrode. Analyst, 114, pp. 943-945, 1989.

[11] Campanella, L., Gregori, E., Tomassetti, M. Salicylic acid determination in cow urine and drugs using a bienzymatic sensor. Journal of Pharmaceutical and Biomedical Analysis, 42, pp. 94-99, 2006.

[12] Bouvrette, P., Luong, J.H.T. A coupled enzymatic assay for salicylate and acetylsalicylate using salicylate hydroxylase and tyrosinase. Analytica Chimica Acta, 335, pp. 169-175, 1996.

[13] Iacob, A., Manea, F., Vaszilcsin, N., Picken, S.J., Schoonman, J. Anodic determination of acetylsalicylic acid at multiwall carbon nanotubes-epoxy composite electrode. International Journal of Electrochemical Science, 10, pp. 5661-5667, 2010.

[14] Remes A., Pop A., Manea F., Baciu A., Picken S.J., Schoonman J., Electrochemical determination of pentachlorophenol in water on multiwall carbon nanotubes-epoxy composite electrode, Sensors, 12(6), pp. 7033-7046, 2012.

[15] Manea, F., Motoc, S., Pop, A., Remes, A., Schoonman, J. Silverfunctionalized carbon nanofiber composite electrodes for ibuprofen detection. Nanoscale Research Letters, 7, pp. 331-335, 2012.

[16] Ramirez-Garcia, S.; Alegret, S.; Cespedes, F.; Forster, R. J. Carbon composite electrodes: surface and electrochemical properties. Analyst 127, pp. 1512-1519, 2002.

[17] Stulik, K., Amatore, C., Holub, K., Marecek, V., Kutner, W. Microelectrodes. Definitions, characterization, and applications. Pure Applied Chemistry 72(8), pp. 1483-1492, 2000. 